\title{
Index of microcirculatory resistance predicts long term cardiac systolic function in patients with STEMI undergoing primary PCI
}

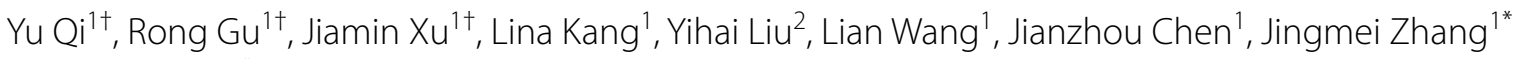 \\ and Kun Wang ${ }^{1 *}$
}

\begin{abstract}
Background: To evaluate the predictive value of the index of microcirculatory resistance (IMR) for long-term cardiac systolic function after primary percutaneous coronary intervention (pPCI) in patients with acute anterior wall ST-segment elevation myocardial infarction (STEMI).
\end{abstract}

Methods: A total of 53 acute anterior wall STEMI patients were included and followed up within 1-year. IMR was measured to evaluate the immediate intraoperative reperfusion. IMR $>40 \mathrm{U}$ was defined as the high IMR group and $\leq 40 \mathrm{U}$ was defined as the low IMR group. Left ventricular ejection fraction (LVEF) was measured by echocardiography at $24 \mathrm{~h}, 1$ month, 3 months, and 1 year after PCI to analyze the correlation between IMR and cardiac systolic function. Heart failure was estimated according to classification within one year.

Results: The ratio of TMPG (TIMI myocardial perfusion grade) 3 ( $85.7 \%$ vs. 52\%, $p=0.015$ ) and STR (ST-segment resolution) $>70 \%$ ( $82.1 \%$ vs. $48 \%, p=0.019)$ were significantly higher in the low IMR group. The LVEF in the low IMR group was significantly higher than that in the high IMR group at 3 months $(43.06 \pm 2.63 \%$ vs. $40.20 \pm 2.67 \%, p<0.001)$ and 1 year $(44.16 \pm 2.40 \%$ vs. $40.13 \pm 3.48 \%, p<0.001)$. IMR was negatively correlated with LVEF at 3 months $(r=-0.1014$, $p=0.0040)$ and 1 year $(r=-0.1754, p<0.0001)$.

Conclusions: The IMR showed significant negative correlation with the LVEF value after primary PCI. The high IMR is a strong predictor of heart failure within 1 year after anterior myocardial infarction.

Keywords: The index of microcirculatory resistance, Acute ST-segment elevation myocardial infarction, Primary percutaneous coronary intervention, Cardiac systolic function

\section{Background}

Acute ST-segment elevation myocardial infarction (STEMI) is one of the most common causes of death in both the developed and developing world [1]. Immediate coronary revascularization by PPCI within $90 \mathrm{~min}$ is the gold standard reperfusion therapy for patients with acute

\footnotetext{
*Correspondence: zhangjm01@163.com; kingwang726@163.com ${ }^{\dagger}$ Yu Qi, Rong Gu and Jiamin Xu have contributed equally to this work 1 Department of Cardiology, Nanjing Drum Tower Hospital, The Affiliated Hospital of Nanjing University Medical School, Nanjing 210008, China Full list of author information is available at the end of the article
}

STEMI [2]. Despite successful reperfusion of the epicardial coronary artery, a significant proportion of patients with STEMI treated with pPCI fail to achieve adequate myocardial reperfusion due to microvascular system injury and dysfunction [3]. Persistent microvascular dysfunction has been associated with worse long-term cardiac function [4].The current metric for quantifying microvascular injury post-STEMI is cardiac magnetic resonance imaging (CMR), which is not readily available during reperfusion in the catheterization laboratory [5]. In this regard, the index of microcirculatory resistance (IMR), an invasive physiological index and readily 
available method with extensive clinical evidence, might be used in the evaluation of microvascular function during pPCI [6]. An IMR > $40 \mathrm{U}$ measured after STEMI has been shown to predict cardiac complications, HF readmission, and mortality [7-9]. The aim of this retrospective study with prospectively enrolled patients with acute anterior wall STEMI was to evaluate the predictive value of IMR for long-term cardiac systolic function after pPCI.

\section{Methods}

\section{Study design and population}

The current study represents a retrospective analysis of patients with acute arterial wall STEMI. Patients were prospectively enrolled in Nanjing Drum Tower Hospital from June 2015 to July 2016 (Chinese Clinical Trial Registry, ChiCTR-ICR-15006964). Details about the RCT trial have been reported previously [10]. The target study population was eligible for participation if they were between 18 and 75 years of age, had anterior wall STEMI and chest pain within $12 \mathrm{~h}$, received emergence $\mathrm{PCI}$ and presented TIMI grade $0-1$ grade during invasive coronary angiography (CAG). The exclusion criteria were as follows: (1) patient undergoing cardiopulmonary resuscitation; (2) patient with heart function grade 3 or 4 (Killip classification) and systolic blood pressure $<90 \mathrm{mmHg}$; (3) with a history of old myocardial infarction or history of coronary artery bypass grafting (CABG); (4) LAD unsuited stent implantation; (5) patients had thrombolysis before pPCI; (6) had contraindication of adenosine triphosphate (ATP); (7) had a history of liver or renal function dysfunction; (8) had major bleeding events during the past 6 weeks; (9) unable to provide informed consent; and (10) had pregnancy or life span $<1$ year. Heart failure was defined as hospitalization because of signs and symptoms of heart failure with noninvasive imaging findings and a discharge diagnosis of heart failure.

\section{Procedure \\ $P C I$}

Before PCI, all the patients took aspirin $300 \mathrm{mg}$ and P2Y12 (clopidogrel $600 \mathrm{mg}$ or ticagrelor $180 \mathrm{mg}$ ). Coronary angiography was performed using standard techniques and the final decision for PCI was at the discretion of the operators. In brief, a guide catheter ( $5 \mathrm{~F}$ to $7 \mathrm{~F}$ ) was used to engage the coronary artery, and a pressure-temperature sensor guidewire was used to measure physiologic indices. After wire crossing, 6F Export AP (Medtronic, USA) thrombus aspiration was performed on high thrombus burden patients. Immediately after successful implantation of drugeluting stents (DES), TIMI and TMPG were recorded at 30 frames per second. The index of microcirculatory resistance (IMR) was detected by fractional flow reserve (FFR) detector (St. Jude Medical, St. Paul, MN, USA).

\section{IMR}

Maximal hyperemia was induced by adenosine $(140 \mu \mathrm{g} /$ $\mathrm{kg} / \mathrm{min}$ ) intravenously administered into the median cubital vein. A 0.014-in floppy Certus Pressure Wire (St. Jude Medical, St. Paul, USA) and modified Pressure Wire-4 software (Radi Medical Systems, Sweden) were used to measure distal coronary pressure and temperature. We placed a pressure wire into the distal LAD and administered ATP to the Pa 15\% decline. Pd, Pa, and FFR were measured and 3 consecutive thermodilution curves were obtained by brisk injection of $3 \mathrm{ml}$ of room temperature saline into the coronary artery, thereby enabling the calculation of mean transit time (Tmin). IMR was calculated by $\mathrm{Pd} \times \mathrm{Tmin}$ [11]. IMR $>40 \mathrm{U}$ was defined as the high IMR group, and $\leq 40 \mathrm{U}$ was defined as the low IMR group $[7,9]$. Cardiac function estimated by ejection fraction (EF) was evaluated by 2-dimensional and 3-dimensional ultrasound during 24-h, 1 month, 3 months and 1 year of follow-up. Heart failure was estimated by NYHA classification and followed with in 1 year.

\section{Therapy and clinical events}

Standard therapy for coronary heart disease was administered before and after the procedure accordingly (aspirin, P2Y12, angiotensin converting enzyme inhibitor/ angiotensin receptor blocker (ACEI/ARB), $\beta$-blocker, statin). Clinical events were obtained at outpatient clinic visits or by telephone contact when needed. The primary outcome was the all-cause mortality or any revascularization events. The secondary endpoint was 1-year MACE, defined as a composite of worsened heart failure, recurrent angina pectoris, recurrent acute myocardial infarction, or cardiac death.

\section{Statistical analysis}

In addition to the study design, the key factor that will influence the power of the retrospective analysis is the sample size. In this research, we have estimated that if the median $\mathrm{EF}$ value at 1 year in IMR $>40 \mathrm{U}$ group is 40.13 (SD, 3.48) and that in $\leq \mathbf{4 0} \mathrm{U}$ group is 44.16 (SD, 2.40), and loss of follow-up is 0.1 , then 9 subjects per group would be needed. All discrete or categorical variables are presented as numbers and relative frequencies (proportions), which were compared with the chi-square test or Fisher's exact test, as appropriate. Continuous variables are presented as the mean $\pm \mathrm{SD}$ or median (interquartile range) according to their distributions, which were compared with Student's t test. Nonnormally distributed continuous variables were compared with the Kruskal-Wallis 
test. Correlations between variables were expressed with Pearson r. Cox proportional hazard regression models

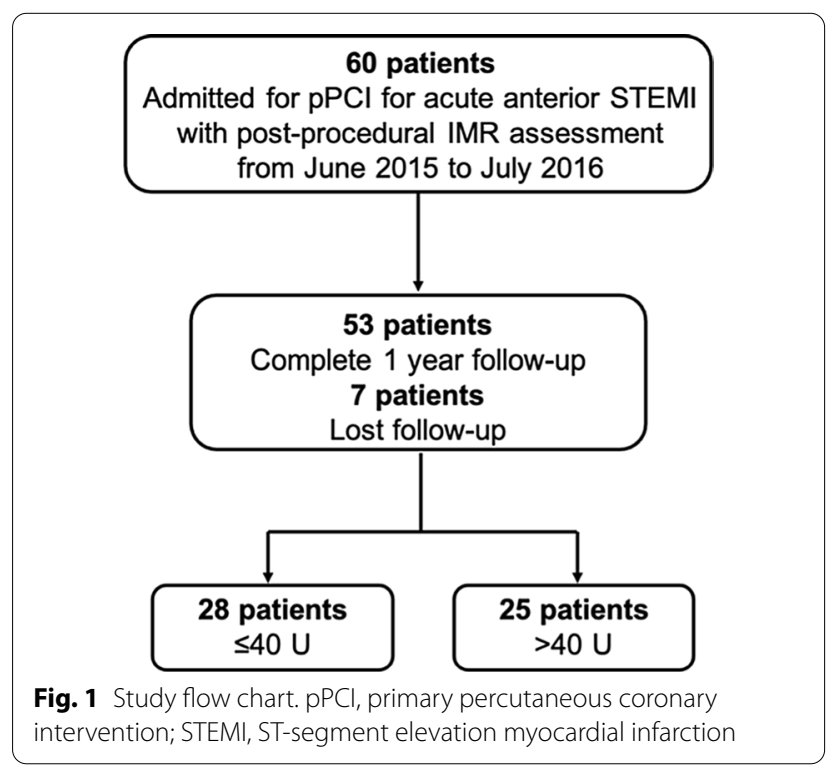

were used to determine predictors of the clinical end points. Statistical analysis was performed with Prism 7, and $p<0.05$ was considered statistically significant.

\section{Results}

Baseline clinical characteristics

A total of 53 anterior wall STEMI patients who were followed up without any death for 1 year were included in the present analysis (Fig. 1). The baseline clinical characteristics are presented in Table 1 . In this study, the high IMR was defined as $>40 \mathrm{U}$, and the low IMR group was $\leq 40 \mathrm{U}$. There was no difference between the two groups in age, hypertension, diabetes, smoking, hyperlipemia, ischemic time or other cardiovascular risk factors.

\section{Angiographic characteristics}

There was no difference in angiography parameters including LAD occlusion, drug eluting stent (DES) and balloon dilation between the two groups, except for a significantly higher percentage of TMPG 3 (85.7\% versus $52 \%, p=0.015)$ and a higher $\mathrm{STR}>70 \%$ ratio $(82.1 \%$

Table 1 Baseline clinical characteristics

\begin{tabular}{|c|c|c|c|}
\hline & $\mathrm{IMR} \leq 40 \mathrm{U}(\mathrm{n}=28)$ & IMR $>40 \cup(n=25)$ & $p$ value \\
\hline Male & $23(82.1)$ & $23(92.0)$ & 0.295 \\
\hline Age (years) & $56.2 \pm 10.5$ & $60.2 \pm 10.2$ & 0.168 \\
\hline Hypertension & $17(60.7)$ & $17(68.0)$ & 0.775 \\
\hline Diabetes mellitus & $7(25.0)$ & $8(32.0)$ & 0.761 \\
\hline Smoking & $21(75.0)$ & $13(52.0)$ & 0.095 \\
\hline Hyperlipemia & $4(14.3)$ & $6(24.0)$ & 0.488 \\
\hline Ischemic time (min) & $246 \pm 180$ & $293 \pm 150$ & 0.293 \\
\hline$D-B(\min )$ & $81.0 \pm 24.2$ & $74.6 \pm 24.1$ & 0.340 \\
\hline $\begin{array}{l}\text { Admission BP } \\
\text { SBP }(\mathrm{mmHg}) \\
\operatorname{DBP}(\mathrm{mmHg})\end{array}$ & $\begin{array}{l}130.4 \pm 15.9 \\
80.4 \pm 16.5\end{array}$ & $\begin{array}{l}126.6 \pm 15.0 \\
80.4 \pm 11.0\end{array}$ & $\begin{array}{l}0.377 \\
0.986\end{array}$ \\
\hline \multicolumn{4}{|l|}{ Periprocedural medication } \\
\hline $\begin{array}{l}\text { Aspirin } \\
\text { P2Y12 } \\
\text { ACEl } \\
\text { Statin } \\
\beta \text {-blocker }\end{array}$ & $\begin{array}{l}28(100.0) \\
28(100.0) \\
28(100.0) \\
28(100.0) \\
28(100.0)\end{array}$ & $\begin{array}{l}25(100.0) \\
25(100.0) \\
25(100.0) \\
25(100.0) \\
25(100.0)\end{array}$ & $\begin{array}{l}- \\
- \\
- \\
- \\
-\end{array}$ \\
\hline Hemoglobin (g/L) & $124.6 \pm 7.7$ & $125.6 \pm 7.4$ & 0.609 \\
\hline Blood glucose (mmol/L) & $6.5 \pm 1.7$ & $6.5 \pm 2.2$ & 0.637 \\
\hline $\mathrm{T}-\mathrm{CHO}(\mathrm{mmol} / \mathrm{L})$ & $5.4 \pm 1.7$ & $5.0 \pm 1.6$ & 0.321 \\
\hline $\mathrm{LDL}-\mathrm{C}(\mathrm{mmol} / \mathrm{L})$ & $2.7 \pm 0.8$ & $2.7 \pm 0.8$ & 0.586 \\
\hline $\mathrm{HbA1c}(\%)$ & $5.7 \pm 0.8$ & $6.1 \pm 1.4$ & 0.214 \\
\hline BNP $(p g / m l)$ & $218.6 \pm 136.5$ & $254.5 \pm 220.1$ & 0.542 \\
\hline IMR & $22.4 \pm 6.6$ & $43.6 \pm 3.7$ & $<0.001$ \\
\hline
\end{tabular}

Values are mean $\pm \mathrm{SD}$ or $\mathrm{n}(\%)$

D-B, door-balloon; SBP, systolic blood pressure; DBP, diastolic blood pressure; ACEI, angiotensin converting enzyme inhibitor; T-CHO, total cholesterol; LDL-C, low density lipoprotein; HbA1c, glycosylated hemoglobin; BNP, B-type natriuretic peptide; IMR, index of microvascular resistance 
versus $48 \%, p=0.019$ ) among patients with low IMR (Table 2)

\section{Cardiac function analysis}

Cardiac function estimated by EF was not different between the two groups at $24 \mathrm{~h}(40.66 \pm 1.58 \%$ versus $39.87 \pm 3.10 \%, p=0.242)$ or 1 month $(41.16 \pm 2.12 \%$ versus $40.52 \pm 2.76 \%, p=0.342$ ). However, the EF value in the low IMR group was significantly higher than that in the high IMR group at 3 months $(43.06 \pm 2.63 \%$ versus $40.20 \pm 2.67 \%, p<0.001)$ and 1 year $(44.16 \pm 2.40 \%$ versus $40.13 \pm 3.48 \%, p<0.001$ ) after PCI (Table 3 and Fig. 2).

\section{Correlation analysis between IMR and LVEF}

IMR had no significant correlation with left ventricular ejection fraction (LVEF) at $24 \mathrm{~h}(\mathrm{r}=-0.0425, p=0.1490)$ and 1 month $(\mathrm{r}=-0.0542, p=0.0651)$ but had a negative correlation with LVEF at 3 months $(\mathrm{r}=-0.1014$, $p=0.0040)$ and 1 year $(\mathrm{r}=-0.1754, p<0.0001)$ (Fig. 3).

\section{The incidence of clinical events}

There wasn't any death among patients. Angina pectoris and heart failure were only major adverse cardiac events. None of the patients had a recurrent myocardial infarction. The incidence of angina was not significantly different between the two groups $(p=0.876)$. However, there were 7 patients diagnosed with heart failure, which was classified II according to NYHA classification. A higher cumulative incidence of heart failure occurred in the $\mathrm{IMR}>40 \mathrm{U}$ group than in the $\leq 40 \mathrm{U}$ group at the 1 -year follow-up $(p=0.011)$. This result suggested that a higher IMR was associated with heart failure (Fig. 4).

Table 2 Angiographic characteristics

\begin{tabular}{|c|c|c|c|}
\hline & $\mathrm{IMR} \leq 40 \mathrm{U}(\mathrm{n}=28)$ & IMR $>40 U(n=25)$ & $p$ value \\
\hline \multicolumn{4}{|l|}{ LAD occlusion } \\
\hline $\begin{array}{l}\text { Proximal } \\
\text { Middle }\end{array}$ & $\begin{array}{l}13(46.4) \\
15(53.6)\end{array}$ & $\begin{array}{l}11(44.0) \\
14(56.0)\end{array}$ & $\begin{array}{l}1.000 \\
1.000\end{array}$ \\
\hline \multicolumn{4}{|l|}{ DES } \\
\hline Number & $1.2 \pm 0.4$ & $1.2 \pm 0.4$ & 0.827 \\
\hline Length (mm) & $29.5 \pm 12.3$ & $31.0 \pm 15.0$ & 0.691 \\
\hline \multicolumn{4}{|l|}{ Balloon dilation } \\
\hline $\begin{array}{l}\text { Predilation } \\
\text { Postdilation }\end{array}$ & $\begin{array}{l}7(25.0) \\
14(50.0)\end{array}$ & $\begin{array}{l}12(48.0) \\
12(48.0)\end{array}$ & $\begin{array}{l}0.095 \\
1.000\end{array}$ \\
\hline TIMI 3 grade & $26(92.9)$ & $20(80.0)$ & 0.234 \\
\hline TMPG 3 grade & $24(85.7)$ & $13(52.0)$ & 0.015 \\
\hline STR $>70 \%$ & $23(82.1)$ & $12(48.0)$ & 0.019 \\
\hline
\end{tabular}

Values are mean \pm SD or $n(\%)$

$L A D$, left anterior descending; DES, drug eluting stent, TIMI, thrombolysis in myocardial infarction, TMPG, STR: ST-segment resolution
Table 3 Cardiac function analysis

\begin{tabular}{lllr}
\hline & $\begin{array}{l}\text { IMR } \leq \mathbf{4 0} \mathbf{U} \\
(\mathbf{n = 2 8 )}\end{array}$ & $\begin{array}{l}\text { IMR }>\mathbf{4 0 ~ U} \\
(\mathbf{n = 2 5 )}\end{array}$ & $\boldsymbol{p}$ value \\
\hline EF value at 24 $\mathrm{h}$ & $40.66 \pm 1.58$ & $39.87 \pm 3.10$ & 0.242 \\
EF value at 1 month & $41.16 \pm 2.12$ & $40.52 \pm 2.76$ & 0.342 \\
EF value at & $43.06 \pm 2.63$ & $40.20 \pm 2.67$ & $<0.001$ \\
$\quad$ 3 months & & & \\
EF value at 1 year & $44.16 \pm 2.40$ & $40.13 \pm 3.48$ & $<0.001$
\end{tabular}

Values are mean \pm SD or $\mathrm{n}(\%)$

$\mathrm{EF}$, ejection fraction

\section{Discussion}

The main findings of our study are: (1) There is a significant negative correlation between IMR and LVEF in patients with anterior wall STEMI at three months and 1-year after primary PCI; (2) The IMR is an independent predictor of heart failure at 1-year after primary PCI.

The purpose of pPCI in acute STEMI was to improve myocardial perfusion and cardiac function [10]. However, half of all treated patients opening a culprit epicardial vessel have a suboptimal result from pPCI, with impaired persistent microvascular dysfunction, such as reperfusion injury or microvascular obstruction (MVO), which predicts worse outcomes in the longer term [12]. Immediate assessment of suboptimal myocardial reperfusion could enable the prompt identification of high-risk patients who could potentially benefit from additional therapy [6].

IMR is an invasive, readily available, quantitative and reproducible, wire-based measure of the minimal achievable coronary microvascular function that exploits the ability of one of the commercially available pressure wire systems to measure both coronary pressure and flow [11, 13]. In patients with STEMI, a distinct advantage of IMR is that it can be measured immediately after pPCI in the catheterization laboratory simultaneous with fractional

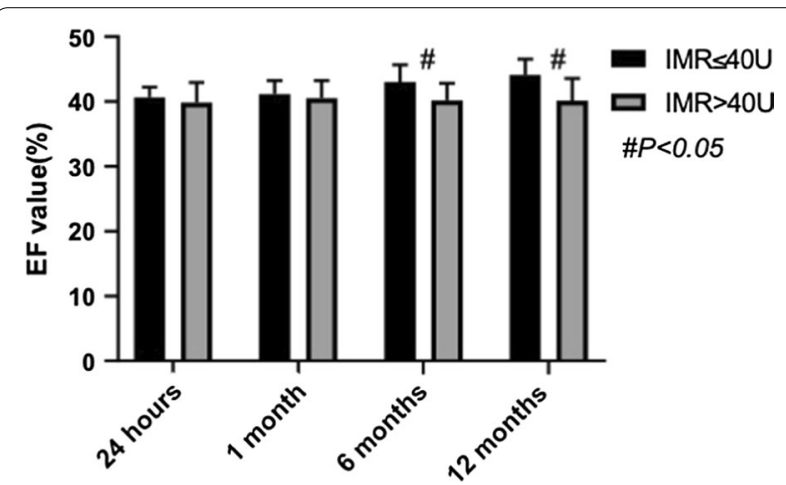

Fig. 2 Follow-up EF values between the IMR $\leq 40 \cup$ group and the IMR $>40 \cup$ group. Values are mean \pm SD 


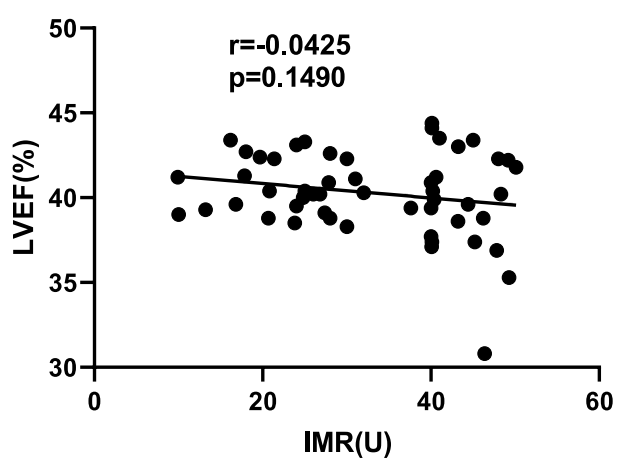

IMR and LVEF value correlation at 24 hours

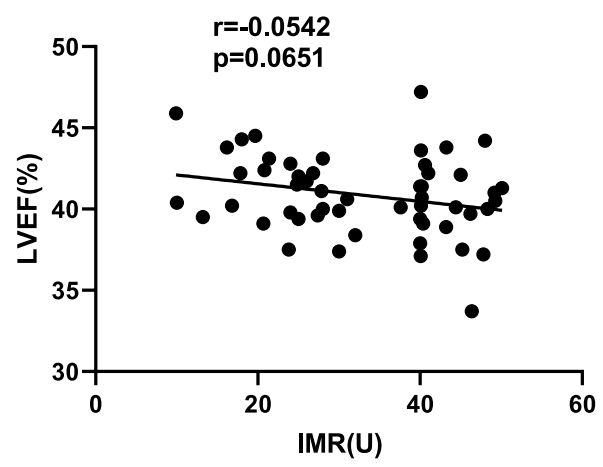

IMR and LVEF value correlation at 1 month

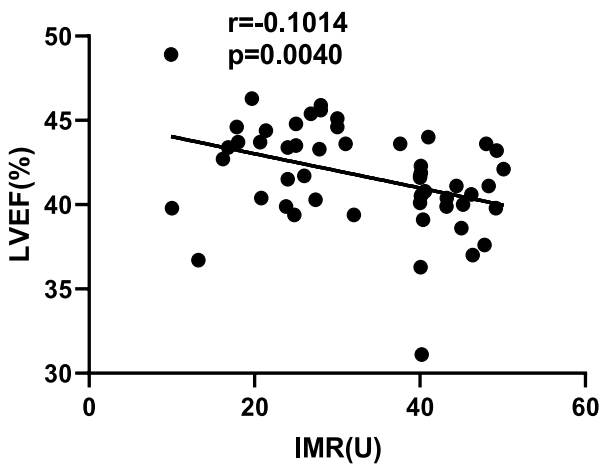

IMR and LVEF value correlation at 3 momths

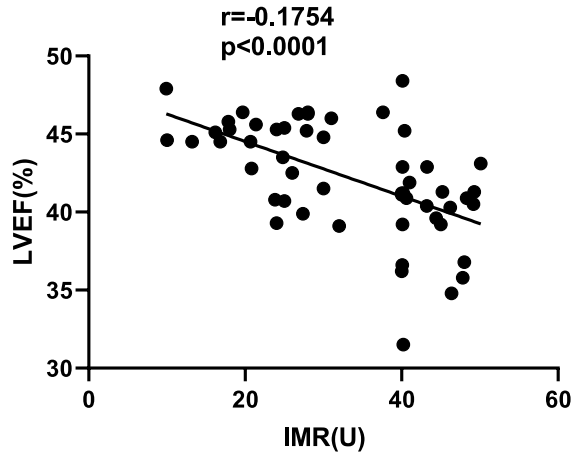

IMR and LVEF value correlation at 1 year

Fig. 3 Correlations analysis between IMR and LVEF. LVEF, left ventricular ejection fraction

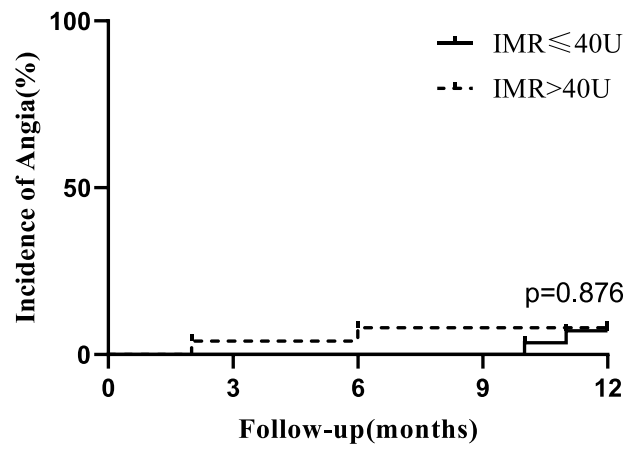

The incidence of Angia during follow-up period

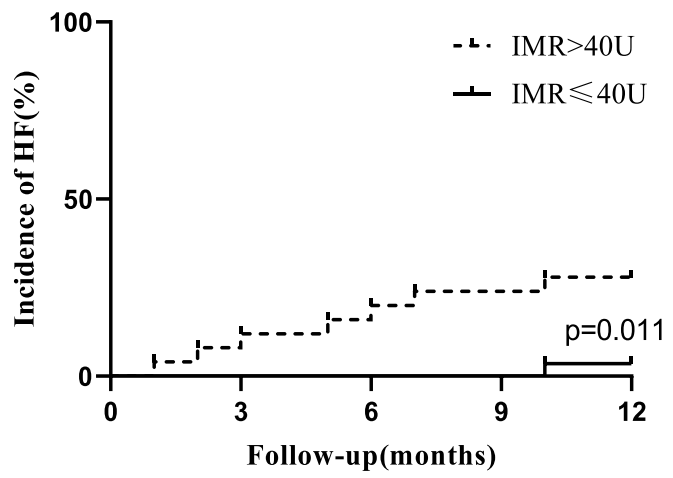

The incidence of HF during follow-up period

Fig. 4 The incidence of heart failure and angina during the follow-up period

flow reserve (FFR) and thereby allow the independent interrogation of both the epicardial artery and the coronary microvasculature at an early enough time when therapeutic intervention may alter the clinical course of patients [14].

There are some other predictors of post -PCI EF in ant MI patients. Hayıroğlu and colleagues assessed the prognostic value of precordial total $\mathrm{Q}$ wave amplitude to precordial total $\mathrm{R}$ wave amplitude ratio $(\mathrm{Q} / \mathrm{R})$ on 354 patients with first acute anterior MI treated with primary $\mathrm{PCI}$, which indicated that $\mathrm{Q} / \mathrm{R}$ is an independent prognostic factor for in-hospital mortality, cardiogenic shock and MACE [15]. Syntax score II (SSII) connects clinical variables with coronary anatomy. Hayıroğlu et al. also reported SSII in 492 patients with STEMI complicated with cardiogenic shock treated with pPCI provide an independent prognostic marker of in-hospital outcomes [16]. While single center nature of these two studies was an important limitation due to the selection bias.

Some studies found that the CK peak concentration with an IMR value below $40 \mathrm{U}$ was relatively low, the ventricular wall motion score could be significantly improved at 3 months, and better clinical prognosis was shown in 
the short-term follow-up [17, 18]. Previous studies have shown that TMPG 3 could independently predict the level of myocardial perfusion [19]. In this study, the ratio of TMPG 3 and STR greater than $70 \%$ was significantly higher in the low IMR group, which further confirmed the association between low IMR and relatively sufficient myocardial perfusion.

We further analyzed the correlation between IMR and LVEF values, and the study showed that IMR and EF values were negatively correlated at 3 months and 1 year after PCI, with statistically significant differences, which was consistent with research of McGeoch [20] showing that IMR was a strong predictor of EF and infarct size. Fearon et al. measured IMR in STEMI patients and showed that IMR was a strong predictor of recovery of left ventricular systolic function after 3 months [17]. Studies have also shown that IMR measured after PCI in patients with acute anterior wall myocardial infarction can predict the myocardial survival, microcirculatory function recovery and cardiac function after 6 months $[18,21,22]$, which is consistent with the results of this study.

Finally, IMR is useful for the early identification of long-term microvascular dysfunction in patients with acute STEMI. Current evidence supports the feasibility of studies using IMR as a predictor of microvascular dysfunction and as a measure of treatment effect. The results of this study confirm that IMR can predict the long-term cardiac systolic function of acute anterior wall myocardial infarction, and the optimization of an emergency PCI strategy based on IMR can improve microcirculatory function, thus improving the long-term cardiac systolic function. These data illustrate an insight from measuring IMR as a tool to guide the stratification of patients for adjunctive therapeutic strategies in acute ST-segment elevation myocardial infarction.

\section{Conclusions}

The results of our study show a significant negative correlation of IMR and LVEF after primary PCI during long term follow-up. Patients with IMR $>40 \mathrm{U}$ are at increased risk of the development of heart failure with in first one year after anterior wall STEMI, which indicated that high IMR may be a useful independent predictor for postmyocardial infarction cardiac function.

\footnotetext{
Abbreviations

ACEl: Angiotensin converting enzyme inhibitor; ARB: Angiotensin receptor blocker; ATP: Adenosine triphosphate; BNP: B-type natriuretic peptide; CABG: Coronary artery bypass grafting; CAG: Coronary angiography; CMR: Cardiac magnetic resonance imaging; D-B: Door-balloon; DBP: Diastolic blood pressure; DES: Drug-eluting stents; FFR: Fractional flow reserve; HbA1c: Glycosylated hemoglobin; HF: Heart failure; IMR: The index of microcirculatory resistance; LAD: Left anterior descending; LDL-C: Low density lipoprotein
}

cholesterol; LVEF: Left ventricular ejection fraction; MACE: Major adverse cardiac events; PPCl: Primary percutaneous coronary intervention; SBP: Systolic blood pressure; STEMI: ST-segment elevation myocardial infarction; STR: STsegment resolution; T-CHO: Total cholesterol; TIMI:Thrombolysis in myocardial infarction; TMPG: TIMI myocardial perfusion grade.

\section{Acknowledgements}

We highly acknowledge the guidance from Prof. Biao Xu from the Department of Cardiology, Nanjing Drum Tower Hospital, State Key Laboratory of Pharmaceutical Biotechnology, The Affiliated Hospital of Nanjing University Medical School, Nanjing, China.

\section{Authors' contributions}

$\mathrm{KW}$ and JZ designed the study, all co-authors participated in the collection of the clinical data and statistical analysis. YQ, RG and JM are co-first author and contributed equally. YQ and KW wrote the manuscript. All authors read and approved the final manuscript.

\section{Funding}

This study was supported by grants from the General Program of National Natural Science Foundation of China (No. 81870291 to R. Gu) and the Youth Program of National Natural Science Foundation of China (No. 81700389 to J. Zhou).

\section{Availability of data and materials}

The datasets generated and/or analyzed during the current study are available from the corresponding author on reasonable request.

\section{Ethics approval and consent to participate}

This study was approved by the Nanjing Drum Tower Ethics Committee (Ethics Number: 2015-060-01). All patients were provided written informed consent and the study protocol was conducted in accordance with the declaration of Helsinki.

\section{Consent for publication}

Not applicable.

\section{Competing interests}

The authors declare no competing interests.

\section{Author details}

${ }^{1}$ Department of Cardiology, Nanjing Drum Tower Hospital, The Affiliated Hospital of Nanjing University Medical School, Nanjing 210008, China. ${ }^{2}$ Department of Cardiology, Nanjing Drum Tower Hospital, Clinical College of Nanjing Medical University, Nanjing 210008, China.

Received: 4 November 2020 Accepted: 22 January 2021

Published online: 02 February 2021

\section{References}

1. Clarke JD, Kennedy R, Duarte Lau F, Lancaster GI, Zarich SW. Invasive evaluation of the microvasculature in acute myocardial infarction: coronary flow reserve versus the index of microcirculatory resistance. J Clin Med. 2019;9(1).

2. Pontone G, Andreini D, Guaricci Al, Guglielmo M, Baggiano A, Muscogiuri G, Fusini L, Fazzari F, Berzovini C, Pasquini A, et al. Association between haptoglobin phenotype and microvascular obstruction in patients with STEMI: a cardiac magnetic resonance study. JACC Cardiovasc Imaging. 2019;12(6):1007-17

3. Niccoli G, Scalone G, Lerman A, Crea F. Coronary microvascular obstruction in acute myocardial infarction. Eur Heart J. 2016;37(13):1024-33.

4. de Waha S, Patel MR, Granger CB, Ohman EM, Maehara A, Eitel I, BenYehuda O, Jenkins P, Thiele H, Stone GW. Relationship between microvascular obstruction and adverse events following primary percutaneous coronary intervention for ST-segment elevation myocardial infarction: an individual patient data pooled analysis from seven randomized trials. Eur Heart J. 2017;38(47):3502-10.

5. van Kranenburg M, Magro M, Thiele $H$, de Waha S, Eitel I, Cochet A, Cottin Y, Atar D, Buser P, Wu E, et al. Prognostic value of microvascular 
obstruction and infarct size, as measured by CMR in STEMI patients. JACC Cardiovasc Imaging. 2014;7(9):930-9.

6. Maznyczka AM, Oldroyd KG, McCartney P, McEntegart M, Berry C. The potential use of the index of microcirculatory resistance to guide stratification of patients for adjunctive therapy in acute myocardial infarction. JACC CardiovascInterv. 2019;12(10):951-66.

7. Carrick D, Haig C, Ahmed N, Carberry J, Yue May VT, McEntegart M, Petrie MC, Eteiba H, Lindsay M, Hood S, et al. Comparative prognostic utility of indexes of microvascular function alone or in combination in patients with an acute ST-segment-elevation myocardial infarction. Circulation. 2016;134(23):1833-47.

8. Fahrni G, Wolfrum M, De Maria GL, Cuculi F, Dawkins S, Alkhalil M, Patel N, Forfar JC, Prendergast BD, Choudhury RP et al. Index of microcirculatory resistance at the time of primary percutaneous coronary intervention predicts early cardiac complications: insights from the OxAMI (Oxford Study in Acute Myocardial Infarction) Cohort. J Am Heart Assoc. 2017;6(11).

9. Fearon WF, Low AF, Yong AS, McGeoch R, Berry C, Shah MG, Ho MY, Kim HS, Loh JP, Oldroyd KG. Prognostic value of the index of microcirculatory resistance measured after primary percutaneous coronary intervention. Circulation. 2013;127(24):2436-41.

10. Wang K, Zhang J, Zhang N, Shen Y, Wang L, Gu R, Xu B, Ji Y. Combined primary $\mathrm{PCl}$ with multiple thrombus burden reduction therapy improved cardiac function in patients with acute anterior myocardial infarction. Int Heart J. 2019;60(1):27-36.

11. Fearon WF, Dash R. Index of microcirculatory resistance and infarct size. JACC Cardiovasc Imaging. 2019;12(5):849-51.

12. Yew SN, Carrick D, Corcoran D, Ahmed N, Carberry J, Teng Yue May V, McEntegart M, Petrie MC, Eteiba H, Lindsay M, et al. Coronary thermodilution waveforms after acute reperfused ST-segment-elevation myocardial infarction: relation to microvascular obstruction and prognosis. J Am Heart Assoc. 2018;7(15):e008957.

13. Cuculi F, De Maria GL, Meier P, Dall'Armellina E, de Caterina AR, Channon KM, Prendergast BD, Choudhury RP, Forfar JC, Kharbanda RK, et al. Impact of microvascular obstruction on the assessment of coronary flow reserve, index of microcirculatory resistance, and fractional flow reserve after ST-segment elevation myocardial infarction. J Am CollCardiol. 2014;64(18):1894-904.

14. Cuculi F, Dall'Armellina E, Manlhiot C, De Caterina AR, Colyer S, Ferreira $\mathrm{V}$, Morovat A, Prendergast BD, Forfar JC, Alp NJ, et al. Early change in invasive measures of microvascular function can predict myocardial recovery following PCI for ST-elevation myocardial infarction. Eur Heart J. 2014;35(29):1971-80.

15. Hayıroğlu M, Uzun AO, Keskin M, Börklü EB, Tekkeşin A, Türkkan C, Kozan Ö. A simple independent prognostic electrocardiography parameter in first acute anterior myocardial infarction; precordial total Q wave/precordial total R wave. J Electrocardiol. 2018;51(1):38-45.

16. Hayıroğlu M, Keskin M, Uzun AO, Bozbeyoğlu E, Yıldırımtürk Ö, Kozan Ö, Pehlivanoğlu S. Predictive value of SYNTAX score II for clinical outcomes in cardiogenic shock underwent primary percutaneous coronary intervention; a pilot study. Int J Cardiovasc Imaging. 2018;34(3):329-36.

17. Fearon WF, Shah M, Ng M, Brinton T, Wilson A, Tremmel JA, Schnittger I, Lee DP, Vagelos RH, Fitzgerald PJ, et al. Predictive value of the index of microcirculatory resistance in patients with ST-segment elevation myocardial infarction. J Am CollCardiol. 2008;51(5):560-5.

18. Lim HS, Yoon MH, Tahk SJ, Yang HM, Choi BJ, Choi SY, Sheen SS, Hwang GS, Kang SJ, Shin JH. Usefulness of the index of microcirculatory resistance for invasively assessing myocardial viability immediately after primary angioplasty for anterior myocardial infarction. Eur Heart J. 2009;30(23):2854-60

19. Gibson CM, Cannon CP, Murphy SA, Ryan KA, Mesley R, Marble SJ, McCabe CH, Van De Werf F, Braunwald E. Relationship of TIMI myocardial perfusion grade to mortality after administration of thrombolytic drugs. Circulation. 2000;101(2):125-30.

20. McGeoch R, Watkins S, Berry C, Steedman T, Davie A, Byrne J, Hillis S, Lindsay M, Robb S, Dargie H, et al. The index of microcirculatory resistance measured acutely predicts the extent and severity of myocardial infarction in patients with ST-segment elevation myocardial infarction. JACC CardiovascInterv. 2010;3(7):715-22.

21. Yoo SH, Yoo TK, Lim HS, Kim MY, Koh JH. Index of microcirculatory resistance as predictor for microvascular functional recovery in patients with anterior myocardial infarction. J Korean Med Sci. 2012;27(9):1044-50.

22. Maznyczka AM, Oldroyd KG, Greenwood JP, McCartney PJ, Cotton J, Lindsay M, McEntegart M, Rocchiccioli JP, Good R, Robertson K, et al. Comparative significance of invasive measures of microvascular injury in acute myocardial infarction. CircCardiovascInterv. 2020;13(5):e008505.

\section{Publisher's Note}

Springer Nature remains neutral with regard to jurisdictional claims in published maps and institutional affiliations.
Ready to submit your research? Choose BMC and benefit from:

- fast, convenient online submission

- thorough peer review by experienced researchers in your field

- rapid publication on acceptance

- support for research data, including large and complex data types

- gold Open Access which fosters wider collaboration and increased citations

- maximum visibility for your research: over $100 \mathrm{M}$ website views per year

At BMC, research is always in progress.

Learn more biomedcentral.com/submissions 